\title{
Exploring the perspectives of healthcare providers that care for non-insured individuals utilizing emergency departments in Toronto
}

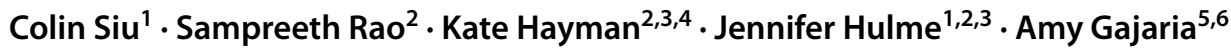

Received: 18 July 2021 / Accepted: 6 January 2022 / Published online: 7 February 2022

○) The Author(s), under exclusive licence to Canadian Association of Emergency Physicians (CAEP)/ Association Canadienne de Médecine d'Urgence (ACMU) 2022

\begin{abstract}
Background Non-insured individuals have different healthcare needs from the general Canadian population and face unique barriers when accessing emergency department (ED) care. This qualitative study aims to better understand the system of emergency care for non-insured individuals from the perspective of healthcare providers.

Methods The study uses a critical realist framework to explore structural factors that facilitate or impede access to care for non-insured individuals. Semi-structured interviews were conducted with 13 interdisciplinary healthcare professionals with experience working with non-insured populations in the ED and in community health centres. Data were analyzed with the use of Braun and Clark's thematic analysis framework and organized into themes through an iterative process until thematic saturation was reached.

Results Healthcare providers face distinct challenges when providing care for non-insured patients including patients presenting with increased illness complexity and providers having to navigate systemic barriers. Interview participants noted stigma and bias, lack of privacy, unclear care pathways, and access to post-ED care as challenges facing non-insured patients. Suggestions to improve the ED experience for non-insured patients include improved staff training, clearer policies, and consistency between hospitals. Most of all, healthcare providers believed that the most effective way to improve the care of non-insured patients would be to make permanent the temporary extension of health coverage to non-insured patients enacted during the COVID-19 pandemic.

Conclusion Interviews with healthcare professionals have highlighted that marginalized populations, including non-insured individuals, face multiple barriers when accessing the ED, especially during the COVID-19 pandemic. At the same time, the temporary extension of health coverage to non-insured patients enacted during the COVID-19 pandemic has likely improved patients' healthcare experience, which we will explore directly with non-insured patients in a future study. In this post-COVID world, we now have an opportunity to learn from our experiences and build a more equitable ED system together.
\end{abstract}

Keywords Medically uninsured · Emergency departments · Qualitative research · Vulnerable populations

\section{Résumé}

Contexte Les personnes non assurées ont des besoins en matière de soins de santé différents de ceux de la population canadienne en général et sont confrontées à des obstacles uniques lorsqu'elles veulent accéder aux soins d'urgence. Cette

Kate Hayman

kate.hayman@uhn.ca

1 Department of Family and Community Medicine, University of Toronto, Toronto, ON, Canada

2 Division of Emergency Medicine, Department of Medicine, University of Toronto, Toronto, ON, Canada

3 Emergency Department, University Health Network, Toronto, ON, Canada
4 Faculty of Medicine, University of Toronto, Toronto, ON, Canada

5 Centre for Addiction and Mental Health, University of Toronto, Toronto, ON, Canada

6 Department of Psychiatry, University of Toronto, Toronto, ON, Canada 
étude qualitative vise à mieux comprendre le système de soins d'urgence pour les personnes non assurées du point de vue des prestataires de soins de santé.

Méthodes L'étude utilise un cadre réaliste critique pour explorer les facteurs structurels qui facilitent ou entravent l'accès aux soins pour les personnes non assurées. Des entretiens semi-structurés ont été menés auprès de 13 professionnels de la santé interdisciplinaires ayant l'expérience du travail avec les populations non assurées aux urgences et dans les centres de santé communautaires. Les données ont été analysées à l'aide du cadre d'analyse thématique de Braun \& Clark et organisées en thèmes par un processus itératif jusqu'à ce que la saturation thématique soit atteinte.

Résultats Les prestataires de soins de santé sont confrontés à des défis distincts lorsqu'ils fournissent des soins à des patients non assurés, notamment des patients présentant une complexité de maladie accrue et des prestataires devant surmonter les obstacles systémiques. Les participants aux entretiens ont noté que la stigmatisation et les préjugés, le manque d'intimité, le manque de clarté des parcours de soins et l'accès aux soins post-urgence sont des défis auxquels sont confrontés les patients non assurés. Les suggestions visant à améliorer l'expérience des patients non assurés aux urgences comprennent une meilleure formation du personnel, des politiques plus claires et une cohérence entre les hôpitaux. Par-dessus tout, les prestataires de soins de santé ont estimé que le moyen le plus efficace d'améliorer les soins aux patients non assurés serait de pérenniser l'extension temporaire de la couverture médicale aux patients non assurés promulguée pendant la pandémie de COVID-19. Conclusion Les entretiens avec les professionnels de la santé ont mis en évidence que les populations marginalisées, notamment les personnes non assurées, sont confrontées à de multiples obstacles lorsqu'elles accèdent aux urgences, en particulier pendant la pandémie de COVID-19. En même temps, l'extension temporaire de la couverture médicale aux patients non assurés, promulguée pendant la pandémie de COVID-19, a probablement amélioré l'expérience des patients en matière de soins de santé, ce que nous explorerons directement auprès des patients non assurés dans une étude future. Dans ce monde post-COVID, nous avons maintenant l'occasion de tirer les leçons de nos expériences et de construire ensemble un système d'urgence plus équitable.

\section{Clinician's capsule}

What is known about the topic?

Non-insured patients in Canada face unique barriers when accessing and obtaining care in Emergency Departments (EDs).

\section{What did this study ask?}

What are the experiences of healthcare providers who provide care to non-insured individuals in Toronto?

\section{What did this study find?}

Caring for non-insured patients in the ED is complex due to medical, financial, and systems level factors.

Why does this study matter to clinicians?

ED care for non-insured patients can be improved by addressing system design and care delivery.

\section{Introduction}

From 2002 to 2011, there was a doubling of Ontario emergency department (ED) visits by non-insured patients [1]. One Ontario ED found that $6 \%$ of patients did not have provincial health coverage [2]. Furthermore, compared to insured patients, non-insured patients are more likely to be triaged into the highest severity categories and to die on arrival in the ED [1]. In March 2020, the Ontario Health Insurance Plan (OHIP) introduced temporary payment mechanisms to facilitate healthcare services for non-insured patients during the COVID-19 pandemic [3].

The initial objective of this qualitative study was to understand the system of emergency care for non-insured individuals through the lens of healthcare providers. The COVID-19 pandemic and resultant policy changes occurred during the study and was identified as a prominent theme. Thus, examining the effects of these policy changes on the care of non-insured individuals became a secondary objective. A qualitative approach was used to explore how ED healthcare providers experience existing care for non-insured individuals and why current care processes may or may not be working [4]. The project is a community needs assessment developed in collaboration with Access Alliance Community Health Centre, whose NonInsured Walk-In Clinic serves over 500 clients annually [5]. Understanding the experiences of front-line providers will help identify gaps in care provision for non-insured individuals.

\section{Methods}

\section{Theoretical framework}

The study was informed by a critical realist framework wherein the research team was interested in the experiences of healthcare providers as well as how this related to the team's own healthcare experience and to existing knowledge $[6,7]$. 


\section{Data collection, recruitment, inclusion, and sampling}

We interviewed 13 healthcare professionals working in urban academic EDs (6) and community health centres (7). Participants included regulated health professionals such as social workers (3), physicians (1) and nurse practitioners (1) as well as non-regulated health professionals such as researchers (1), bioethicists (1), administrative coordinators (2), patient care coordinators (1), settlement workers (2) and case managers (1). Thematic saturation was reached when: (i) no new themes were generated after multiple team meetings, and (ii) team members agreed there was no missing content from their experiences providing emergency care to non-insured individuals nor from the literature. Semi-structured interviews were conducted between August 2019 and August 2020. Recruitment was through self-selected convenience and snowball sampling. The study was approved by the University of Toronto Research Ethics Board (Protocol 37733).

\section{Data analysis}

Data were analyzed consistent with Braun and Clark's thematic analysis framework [8]. Data was organized into themes through an iterative process until thematic saturation was reached. Three members of the research team completed line-by-line coding to generate codes and themes. The full research team met to ensure thematic saturation and finalize themes. Triangulation was achieved through multiple individuals completing close coding and numerous team meetings to reach consensus on discordant views.

\section{Results}

We generated three themes from the interviews: (a) challenges for healthcare providers in caring for non-insured individuals, (b) non-insured individuals' experience of, and access to, healthcare, and (c) suggestions for future improvement.

\section{Challenges for healthcare providers}

\section{Illness complexity}

Healthcare providers highlighted the additional burden of caring for non-insured populations. They noted that noninsured patients often present with complex health needs for multiple reasons: (a) fear of being unable to pay means patients delayed care until illnesses were advanced, (b) patients lack access to primary care, (c) newcomers to Canada lack knowledge of how to navigate the health system, and (d) presenting with advanced disease due to poor access to healthcare in their country of origin.
"I met some people who had really advanced complex health conditions that maybe they had put off for quite a while[...] So by the time they did come to the hospital, they were quite sick." (Regulated health professional, ED).

\section{Competing demands}

Healthcare providers noted that system level factors complicated care for non-insured patients. Balancing the costs of care incurred by patients while not compromising clinical outcomes created moral distress. Care providers highlighted frequently changing coverage policies for non-insured individuals and needing to advocate for patients.

"And oftentimes it's an ethical dilemma when the finance department might say you know, you can't go ahead further for this kind of treatment or [say] discharge them right now despite not having enough treatment completed. And the team is like I'm, you know, this is a, this is a quandry for me, I can't do that. I have professional obligations." (Non-regulated health professional, ED).

\section{Healthcare access and experience of care}

\section{Impact of policy}

Participants identified a lack of clarity regarding ED policies for non-insured patients. Non-insured patients could fall into different categories with varying implications for accessing care, including Canadian residents who are experiencing homelessness and lack ID and those lacking formal status in Canada. Participants noted that the responsibility of categorizing non-insured patients is placed on registration clerks with limited guidance. Additionally, participants commented that the approach to non-insured individuals can vary by hospitals even in the same city.

"The only thing that the registration clerk might in that moment ask is for basic name, address, OHIP, proof of payment, whatever, if you don't have OHIP. And at that point the patient feels compelled to say "I don't have, but I [need] care right now" [...], and the admin person won't know how to deal with it." (Non-regulated health professional, ED).

\section{Stigma and bias}

Participants discussed how a lack of training, constantly changing health coverage policies, and competing priorities for healthcare providers can lead to bias and stigma 
towards non-insured patients. They described that ED staff may engage in informal "workarounds" to assist non-insured patients, but this happens on an ad-hoc basis and is open to implicit bias.

"And a lack of training and staff turnaround. Because, you know, like you might have someone who's trained and knows what to do [with non-insured patients]. But the following week if they're sick and there's someone filling in for them, they're not necessarily equipped to know what to do with a non-insured patient in terms of billing processes right? And then that's when their own personal values come in." (Non-regulated health professional, community health centre).

\section{Privacy concerns}

Participants noted multiple privacy concerns including noninsured individuals' fears that accessing healthcare could result in information being shared with authorities, leading to deportation or immigration challenges. Non-insured individuals are also more likely to have exposure to trauma, and participants noted that the ED lacks privacy for these conversations.

\section{Post-ED care}

ED staff noted non-insured individuals may have more complex ED discharges as they are unable to pay for prescriptions and have difficulty accessing specialty services. Access to homecare supports for non-insured patients is also a barrier.

\begin{abstract}
"However, when it gets sticky is when they need something other than being in the emergency department.

So someone with a broken jaw who needs surgery, they're not gonna do surgery because they're not gonna get paid. It's gonna be more complicated to book OR without insurance and all that stuff." (Regulated health professional, ED).
\end{abstract}

\section{Care facilitators}

Being connected to a community health centre prior to accessing care improves care in the ED and post-discharge supports for non-insured individuals in Toronto. Community health centre connections also could facilitate transportation to EDs, and support navigating payments.
"It does fall through the cracks unless you have somebody who's really on top of their care." (Regulated health professional, community health centre).

\section{Suggestions for improvement}

Participants believed that increased training for all staff, clearer policies, and consistency between hospitals would improve the experience for non-insured patients. Care providers believed better understanding of options to decrease the financial burden on non-insured patients would improve patient care. Ultimately, care providers felt that the most effective way to ease demands on healthcare providers and improve care would be to make permanent the temporary extension of health coverage to non-insured patients enacted during the COVID-19 pandemic.

"I even had people who got surgeries during this time... it was so amazing. You can send somebody to Emerg and not worry about them, like politics or whatever. So they were being seen and it was perfect." (Regulated health professional, community health centre).

\section{Discussion}

This is the first qualitative Canadian study looking at the experiences of non-insured patients in the ED. The study's strengths lie in the unique collaboration with Access Alliance to inform community needs and in the inclusion of a range of healthcare provider stakeholders.

The study highlights the increased medical and social complexity of non-insured patients, consistent with existing literature $[1,9,10]$. Novel findings are the following opportunities for structural changes to improve healthcare and decrease provider moral distress when caring for noninsured patients in Canada: increased training for providers, providing healthcare coverage to non-insured individuals, and strengthening hospital and community connections (Table 1).

This study was limited by the COVID-19 pandemic which made patient interviews unfeasible. An important consideration for future research would be to elicit information from patients themselves. 
Table 1 Key themes and suggestions for improving the ED care of non-insured patients

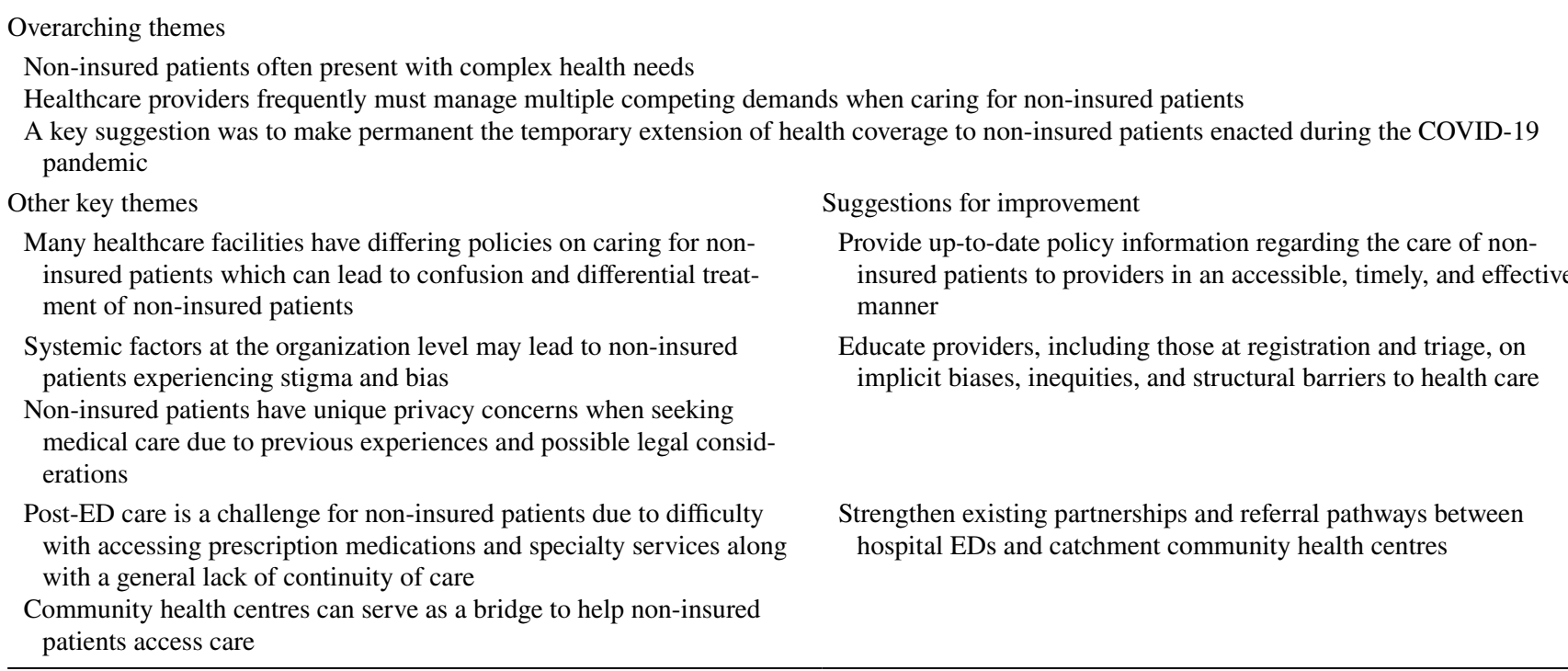

\section{Conclusion}

The COVID-19 pandemic has brought to light the health inequities that marginalized communities face. As we recover from the pandemic, we have an exciting opportunity to take these lessons learned to build a more equitable healthcare system together.

Supplementary Information The online version contains supplementary material available at https://doi.org/10.1007/s43678-022-00263-7.

Acknowledgements The authors would like to acknowledge the expertise that our community partner, Access Alliance Community Health Centre, provided throughout the study with special thanks to the Access Alliance research team including Mr. Clifford Ledwos and Dr. Akm Alamgir. The authors would also like to thank Ms. Elayna Fremes and Alexandra McKnight for their administrative support of this study.

Author contributions All authors contributed to the study conception and design. Material preparation, data collection and analysis were performed by CS, SR, and AG. The first draft of the manuscript was written by CS, SR, and AG and all authors commented on previous versions of the manuscript. All authors read and approved the final manuscript.

Funding This study was funded by a grant from the University Health Network in Toronto.

\section{Declarations}

Conflict of interest The authors declare that they have no conflict of interest.

Consent to participate Informed consent was obtained from all individual participants included in the study.

Consent to publish All individual participants signed informed consent regarding publishing their data.
Ethics approval Approval was obtained from the ethics committee of the University of Toronto (Protocol 37733). The procedures used in this study adhere to the tenets of the Declaration of Helsinki.

\section{References}

1. Hynie M, Ardern CI, Robertson A. Emergency room visits by uninsured child and adult residents in Ontario, Canada: what diagnoses, severity and visit disposition reveal about the impact of being uninsured. J Immigr Minor Health. 2016;18(5):948-56.

2. Open Doors-University Health Network. University Health Network. 2009.

3. Health Services Branch, Ministry of Health. INFOBulletin 4749, Re: COVID-19 expanding access to ohip coverage and funding physician and hospital services for uninsured patients. Ontario Ministry of Health/Ministry of Long-Term Care. 2020.

4. McLane P, Chan T. Stories, voices, and explanations: how qualitative methods may help augment emergency medicine research. CJEM. 2018;20(4):491-2.

5. Narayan S. Non-insured walk-in clinic annual report. Access Alliance Multicultural Health and Community Services. 2017.

6. Bhaskar R, Danermark B. Metatheory, interdisciplinarity and disability research: a critical realist perspective. Scand J Disabil Res. 2006;8(4):278-97.

7. Fletcher AJ. Applying critical realism in qualitative research: methodology meets method. Int J Soc Res Methodol Theory Pract. 2017;20(2):181-94.

8. Braun V, Clarke V. Using thematic analysis in psychology. Qual Res Psychol. 2006;3(2):77-101.

9. Braveman PA, Egerter S, Bennett T, Showstack J. Differences in hospital resource allocation among sick newborns according to insurance coverage. JAMA. 1991;266(23):3300-8.

10. Schwartz DA, Hui X, Schneider EB, Ali MT, Canner JK, Leeper WR, et al. Worse outcomes among uninsured general surgery patients: does the need for an emergency operation explain these disparities? Surgery. 2014;156(2):345-51. 